\title{
Berberine decelerates glucose metabolism via suppression of mTOR-dependent HIF-1 $\alpha$ protein synthesis in colon cancer cells
}

\author{
LIYUAN MAO $^{1 *}$, QIONGYUN CHEN ${ }^{1 *}, \mathrm{KE} \mathrm{GONG}^{1}$, XIAOLIN XU ${ }^{1}$, YUROU XIE $^{1}$, WENQING ZHANG ${ }^{1}$, \\ HANWEI CAO ${ }^{1}$, TIANHUI $\mathrm{HU}^{1}$, XIAOTING HONG ${ }^{1,2}$ and YAN-YAN ZHAN ${ }^{1}$ \\ ${ }^{1}$ Cancer Research Center, and ${ }^{2}$ Department of Basic Medicine, Medical College of Xiamen University, \\ Xiamen, Fujian 361102, P.R. China
}

Received October 13, 2017; Accepted March 8, 2018

DOI: $10.3892 /$ or.2018.6318

\begin{abstract}
Hyperactivated glucose uptake and glycolytic metabolism are considered as a hallmark of cancer. Berberine, a natural alkaloid with tumor-selective anticancer effects, has been shown to promote glucose uptake in metabolic tissues and cells. However, whether and how berberine regulates the glucose metabolism of cancer cells are still poorly understood. In the present study, we revealed that berberine, which suppressed the growth of colon cancer cell lines HCT116 and $\mathrm{KM} 12 \mathrm{C}$, greatly inhibited the glucose uptake and the transcription of glucose metabolic genes, GLUT1, LDHA and HK2 in these two cell lines as assessed by RT-qPCR. A mechanistic study further indicated that the protein expression but not mRNA transcription of HIF-1 $\alpha$, a well-known transcription factor critical for dysregulated cancer cell glucose metabolism, was dramatically inhibited in berberine-treated colon cancer cell lines. Using western blot analysis, this regulation appears to occur via protein synthesis but not protein stability as blockade of HIF-1 $\alpha$ protein degradation by hypoxia mimic desferrioxamine (DFX) or proteasome inhibitor MG132 did not affect berberine's effect. In addition, mTOR signaling previously reported to regulate HIF-1 $\alpha$ protein synthesis was further found to be suppressed by berberine. Taken together, our results indicated that berberine
\end{abstract}

Correspondence to: Dr Xiaoting Hong, Department of Basic Medicine, Medical College of Xiamen University, 4221 South Xiang'an Road, Xiamen, Fujian 361102, P.R. China

E-mail: xthong@xmu.edu.cn

Dr Yan-Yan Zhan, Cancer Research Center, Medical College of Xiamen University, 4221 South Xiang'an Road, Xiamen, Fujian 361102, P.R. China

E-mail: yyzhan@xmu.edu.cn

${ }^{*}$ Contributed equally

Key words: berberine, glucose uptake, colon cancer, HIF-1 $1 \alpha$, mTOR inhibits overactive glucose metabolism of colon cancer cells via suppressing mTOR-depended HIF- $1 \alpha$ protein synthesis, which provided not only a novel mechanism involved in berberine's tumor-specific toxicity but also a theoretical basis for the development of berberine for colon cancer treatment.

\section{Introduction}

Overactive glucose metabolism termed as the "Warburg effect' plays a vital role in cancer growth. Tumor cells tend to have a higher level of glucose uptake and glycolytic metabolism to satisfy themselves with a high energy need (1). Therefore, targeting glucose metabolism is considered as a therapeutic approach for cancer treatment (2). Inhibition of glucose uptake and metabolism that aim to generate an energy deprivation state can facilitate the effect of other anticancer therapies.

Berberine is a botanical alkaloid from the Ranunculaceae and Papaveraceae plant families. It is the active component of Chinese medicine Rhizoma coptidis, and has been widely used for treating metabolic diseases, including obesity and diabetes $(3,4)$. One of the rationale for this treatment is that berberine increased cellular glucose uptake and metabolism (5-7). On the other hand, the effect of berberine against cancer has also been widely explored (8). Numerous studies have demonstrated that berberine inhibits the growth of broad types of tumor cells, and is thus recognized as a potential multispectrum anticancer therapeutic agent (8-10). Given that cancer growth needs overspeed glucose metabolism, it raised a problem that berberine's promoting effect on glucose metabolism appears to be contradictory to its anticancer effect. However, as most of the studies on berberine's glucose metabolism function were carried out in non-tumor metabolic tissues and cells, we hypothesized that berberine may have a distinct role on cellular glucose metabolism in cancer cells.

In the present study, we investigated the berberine's effects on colon cancer cell lines. We revealed that berberine inhibits glucose uptake and reduces the transcription of glucose metabolism relative genes in colon cancer cells. These effects may be mediated by the inhibition of HIF-1 $\alpha$ protein synthesis through suppression of mTOR pathway. 


\section{Materials and methods}

Materials. Berberine, anti-rabbit IgG, anti-mouse $\operatorname{IgG}$ and anti- $\beta$-actin IgG were purchased from Sigma-Aldrich(Shanghai, China). Antibodies for HIF-1 $\alpha$ (cat. no. 14179), mTOR (cat. no. 2983) and phospho-mTOR (Ser2448) (cat. no. 2971) were purchased from Cell Signaling Technology Inc. (Beverly, MA, USA). 2-(N-(7-nitrobenz-2-oxa-1,3-diazol-4-yl) amino)-2-deoxyglucose (2-NBDG) was purchased from Thermo Fisher Scientific (Eugene, OR, USA). All other reagents including DFX and MG132 were obtained from Sigma-Aldrich unless stated otherwise.

Cell lines and cell culture. Human colon cancer cell lines HCT116 and KM12C were obtained from the Cell Bank of the Chinese Academy of Sciences (Shanghai, China). HCT116 cells were cultured in McCoy'5A medium (Thermo Fisher Scientific, Hudson, NH, USA). KM12C cells were cultured in Dulbecco's modified Eagle's medium (DMEM; Thermo Fisher Scientific). All the medium was supplemented with $10 \%$ fetal bovine serum (FBS; GE Healthcare Life Sciences, HyClone Laboratories, Logan, UT, USA), $100 \mu \mathrm{g} / \mathrm{ml}$ of streptomycin (Life Technologies; Thermo Fisher Scientific) and 100 units of penicillin.

MTTassay. Cell viability was detected using the 3-(4,5-dimethyl thiazol-2-yl)-2,5-diphenyltetrazolium bromide (MTT) assay. Cells were seeded at a density of $1 \times 10^{4}$ cells/well in 96-well plates and then treated with $0-100 \mu \mathrm{M}$ berberine as indicated. At the time-points ( $24 \mathrm{~h}$ for HCT116 cells and $15 \mathrm{~h}$ for KM12C cells), $50 \mu 1$ of $5 \mathrm{mg} / \mathrm{ml}$ MTT solution was added to each well and incubated at $37^{\circ} \mathrm{C}$ for $4 \mathrm{~h}$. The formazan crystals formed were then dissolved in $150 \mu$ l of dimethyl sulfoxide (DMSO), and the absorbance of the solution was then obtained on a microplate reader at $\lambda 570 \mathrm{~nm}$. Results are presented as percentage loss of cell viability compared with the control.

Colony-forming assay. Cells were seeded in a 6-well plate one day before the experiment. Cells were treated with berberine for $24 \mathrm{~h}$ (HCT116) or $15 \mathrm{~h}$ (KM12C), and then washed with phosphate-buffered saline (PBS), harvested by trypsinization, counted, and were seeded into 6 -well dishes at 600 cells/well. The cells were incubated for another 10 days, fixed and stained with $1 \%$ crystal violet in ethanol. Then, the colonies in 6-well plates were photographed using a scanner (Epson Perfection V330; Epson Corp., Nagano, Japan).

Glucose uptake assay. Glucose uptake of cells was measured by $2-\mathrm{NBDG}$ uptake as previously described (11). Briefly, the cells were seeded in a 12 -well plate at a density of $70-80 \%$, and treated with $0-100 \mu \mathrm{M}$ of berberine for $24 \mathrm{~h}$ (HCT116) or $15 \mathrm{~h}$ (KM12C). After treatment, the cells were harvested and resuspended in Krebs-Ringer's HEPES Buffer (KRB) solution, and incubated with $100 \mathrm{nmol} / 12-\mathrm{NBDG}$ at $37^{\circ} \mathrm{C}$ in $5 \% \mathrm{CO}_{2}$ for $30 \mathrm{~min}$. The 2-NBDG uptake reaction was terminated by removing the incubation medium and washing the cells twice with pre-cold PBS. Cells were resuspended in $1 \mu \mathrm{g} / \mathrm{ml}$ propidium iodide (PI) solution to exclude dead cells. Glucose uptake was determined by measuring the fluorescence intensity of 2-NBDG in PI-negative cells.
Real-time quantitative PCR. Cells were seeded in a 6-well plate at a density of $70-80 \%$ and treated with $0-100 \mu \mathrm{M}$ berberine for $24 \mathrm{~h}$ (HCT116) or $15 \mathrm{~h}$ (KM12C). Total RNA was isolated using TRIzol reagent (Takara Biotechnology Co., Ltd., Dalian, China). RNA was reverse-transcribed into cDNA using PrimeScript ${ }^{\mathrm{TM}}$ RT reagent kit (Takara Biotechnology Co., Ltd.) according to the manufacturer's protocol. Real-time quantitative polymerase chain reaction (PCR) was carried out with the SYBR-Green I fluorescent dye method (SYBR ${ }^{\circledast}$ Premix Ex Taq ${ }^{\mathrm{TM}}$ II; Takara Biotechnology Co., Ltd.) and the StepOnePlus Real-Time PCR apparatus (Applied Biosystems; Thermo Fisher Scientific). The sequences of primers used were as follows: Forward, 5'-TATTGCACTGCACAGGCC ACATTC-3' and reverse, 5'-TGATGGGTGAGGAATGGG TTCACA-3' for HIF- $1 \alpha$; forward, 5'-GGCATTGATGACTCC AGTGTT-3' and reverse, 5'-ATGGAGCCCAGCAGCAA-3' for GLUT1; forward, 5'-TCACGGAGCTCAACCATGAC-3' and reverse, 5'-CTGCAGTAGGGTGAGTGGTG-3' for HK2; forward, 5'-GCCCGACGTGCATTCCCGATTCCTT-3' and reverse, 5'-GACGGCTTTCTCCCTCTTGCTGACG-3' for LDHA; forward, 5'- CGTGTACTACAATGAGGCTGC-3' and reverse, 5'-CTGGTCTGAAGATCTGGCCG-3' for $\beta$-tubulin. The amplification specificity was checked by melting curve analysis. The relative expression of miRNA was calculated by the $2^{-\Delta \Delta C t}$ method as described by Livak and Schmittgen (12).

Western blotting. Cells at $60-80 \%$ confluence were washed with PBS and lysed directly into SDS-PAGE loading buffer. A total of $20 \mu \mathrm{g}$ of protein was analyzed by SDS-PAGE and transferred to PVDF membranes. All primary antibodies were used at 1:1,000 in 5\% milk in Tris-buffered saline with $0.05 \%$ Tween. Immunopositive bands were visualized by Amersham ECL $^{\mathrm{TM}}$ Plus Western Blotting Detection kit (GE Healthcare, Chicago, IL, USA).

Statistical analysis. The SigmaPlot version 11.0 software package (Systat Software, Inc., San Jose, CA, USA) was used for statistical analysis. The results are presented as mean \pm standard error (SEM). Data were analyzed by one way analysis of variance (ANOVA) or the Student's t-test. $\mathrm{P}<0.05$ was considered to indicate a statistically significant result.

\section{Results}

Berberine inhibits glucose uptake and cell growth in colon cancer cells. Berberine has been shown to enhance glucose uptake in cell lines including 3T3 adipose cells $(5,13)$ and L6 myotubes (7). To test its effect on colon cancer cells, two colon cancer cell lines, HCT116 and KM12C, were treated with 0 , $6.25,12.5,25,50$ and $100 \mu \mathrm{M}$ of berberine for 24 or $15 \mathrm{~h}$ respectively, and the glucose uptake of these cell lines was assessed. In contrast to berberine's reported effect of enhancing glucose update, we unexpectedly revealed that berberine inhibited glucose uptake in the colon cancer cell lines. As shown in Fig. $1 \mathrm{~A}$ and $\mathrm{B}$, treatment with the different concentrations of berberine significantly reduced glucose uptake in these two cell lines. At concentrations between 6.25 and $100 \mu \mathrm{M}$, berberine decreased glucose uptake of HCT116 by $40-90 \%$, and by $10-75 \%$ in KM12C cells, which was slightly less sensitive. We then validated the anticancer effect of berberine 
A

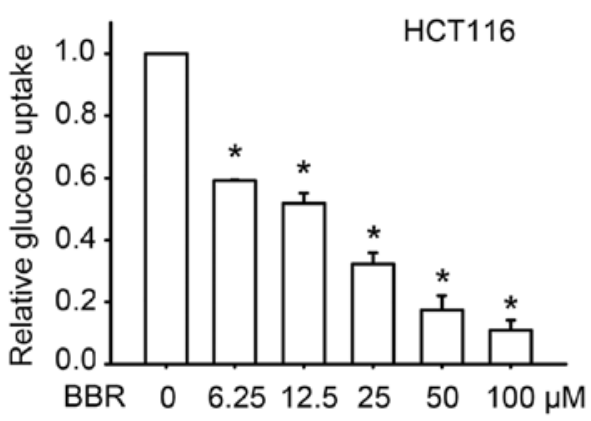

C

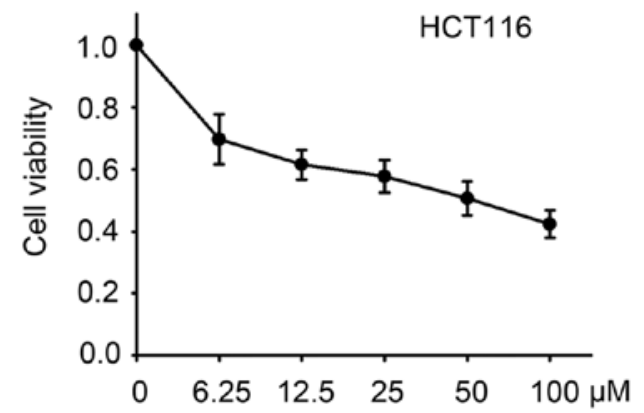

B
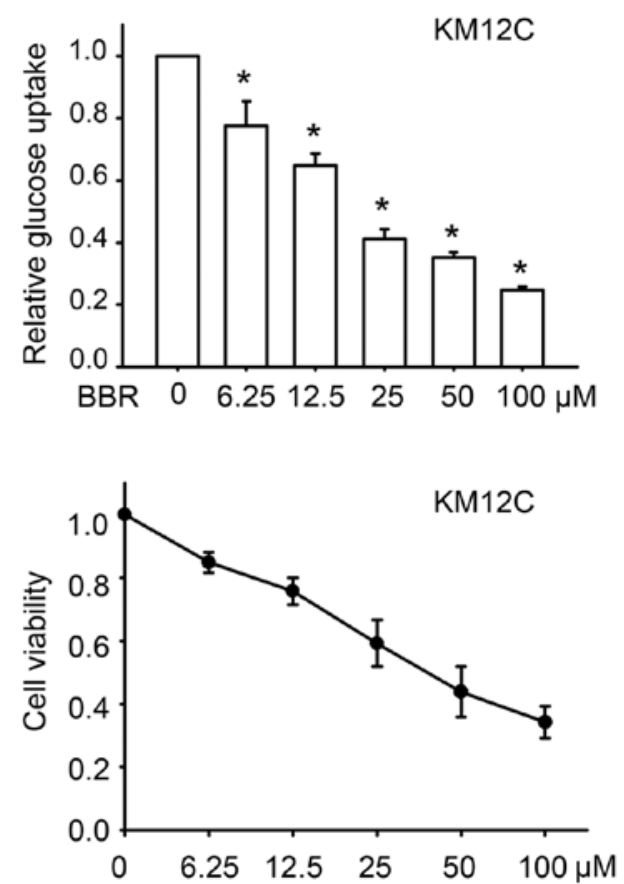

25

50

$100 \mu \mathrm{M}$

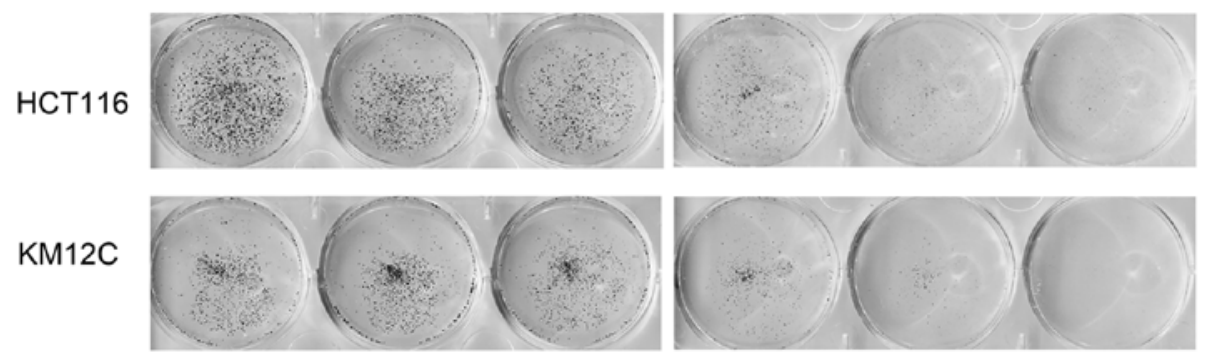

Figure 1. Berberine suppresses glucose uptake and cell growth in colon cancer cells. (A and B) 2-NBDG glucose uptake analysis of the cell glucose uptake of colon cancer cells following treatment of $0-100 \mu \mathrm{M}$ berberine (BBR) for $24 \mathrm{~h}$ (HCT116) or $15 \mathrm{~h}(\mathrm{KM} 12 \mathrm{C})$. Data are expressed as mean $\pm \mathrm{SEM}, \mathrm{n}=3,{ }^{*} \mathrm{P}<0.05$. (C and D) Cells were treated with 0-100 $\mu \mathrm{M}$ of BBR for $24 \mathrm{~h}$ (HCT116) or $15 \mathrm{~h}$ (KM12C), and cell viability was then assessed by MTT assay. (E) Typical images of the colony forming assay to determine the effect of 0-100 $\mu \mathrm{M}$ BBR for $24 \mathrm{~h}$ (HCT116) or $15 \mathrm{~h}$ (KM12C) on growth of colon cancer cells.

by detecting cell proliferation after berberine treatment. MTT assay indicated that berberine decreased the viability of the HCT116 and KM12C cells in a concentration-dependent manner (Fig. 1C and D). To further investigate the long-term effect of berberine on cell growth, colony forming assay was performed. Similarly, berberine inhibited the growth of colon cancer cells, manifested as the reduction in the number of colonies of the HCT116 and KM12C cells in a concentration-dependent manner (Fig. 1E). These results indicated that berberine inhibits glucose uptake in colon cancer cells, and these effects may contribute to its antitumor effect.

Berberine inhibits the transcription of glucose metabolismrelated gene in colon cancer cells. We then further investigated the mechanism by which berberine inhibits glucose uptake. Glucose transporter 1 (GLUT1) is the dominate glucose transport gene in colon cancer cells $(14,15)$, which facilitates the transport of glucose across the plasma membranes. We examined the transcription of GLUT1 after berberine treatment. As shown in Fig. 2A and B, treatment with berberine inhibited the
mRNA level of GLUT1 in a concentration-dependent manner. At concentrations between 6.25 and $25 \mu \mathrm{M}$, berberine decreased the mRNA level of GLUT1 in the HCT116 cells by $50-70 \%$, and similar to the data of glucose uptake, KM12C cells were less sensitive. Berberine $(6.25-25 \mu \mathrm{M})$ reduced the mRNA level of GLUT1 by $10-35 \%$ in the KM12C cells. These data indicated that the inhibitory effect of berberine on glucose uptake may be mediated by the transcription inhibition of GLUT1.

The altered energy metabolism of cancer cells is not only attained by enhancing glucose uptake, but also a higher rate of glycolysis. Thus, we examined the transcription of two glycolytic enzymes following berberine treatment: Lactate dehydrogenase A (LDHA) and hexokinases 2 (HK2). LDHA catalyzes the inter-conversion of pyruvate and L-lactate with concomitant inter-conversion of NADH and NAD ${ }^{+}$. HK2 phosphorylates glucose to produce glucose-6-phosphate (G6P), the first step in most glucose metabolism pathways. As shown in Fig. 2C-F, treatment with $0-100 \mu \mathrm{M}$ berberine inhibited the mRNA levels of LDHA and HK2 in a concentration-dependent manner as assessed by qPCR. Thus, our data indicated that 
A

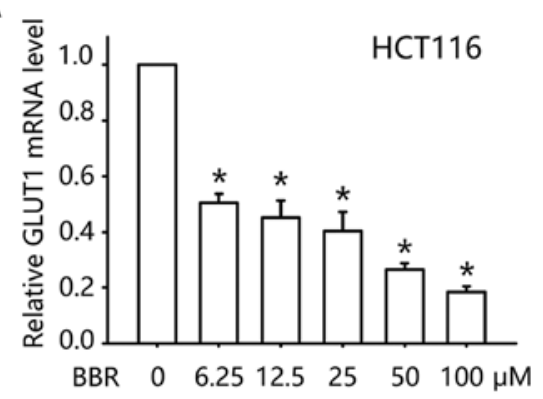

C

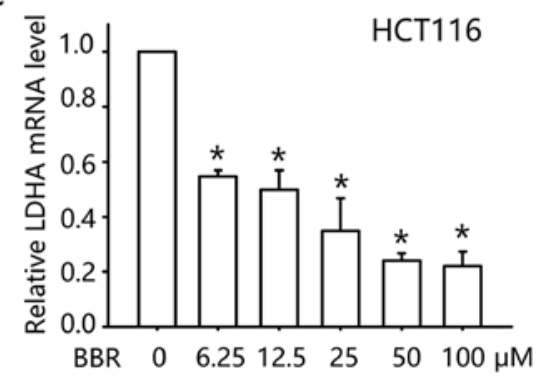

$\mathrm{E}$

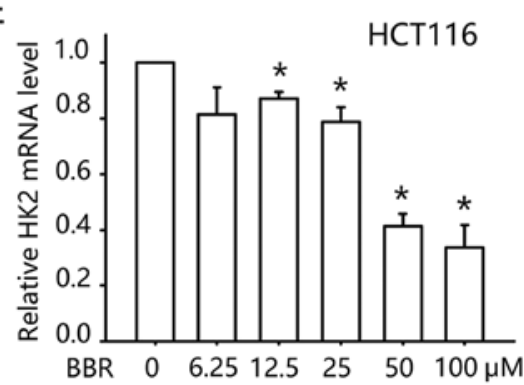

B

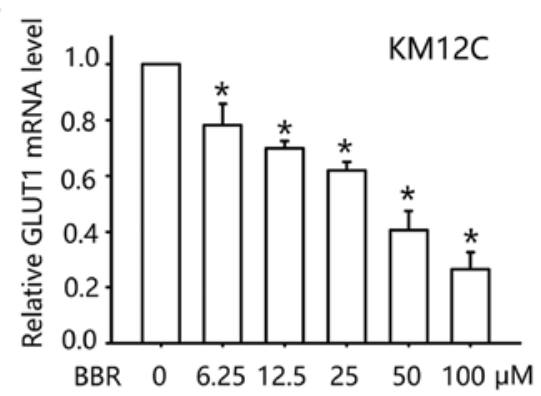

$\mathrm{D}$

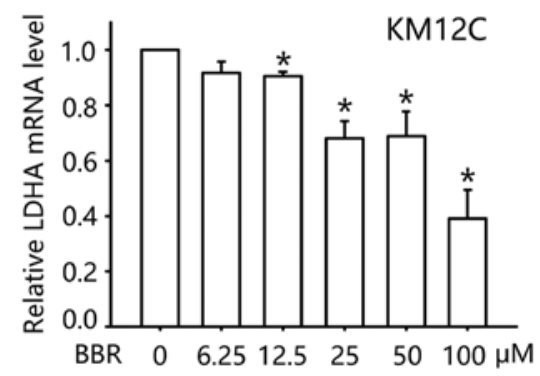

$\mathrm{F}$

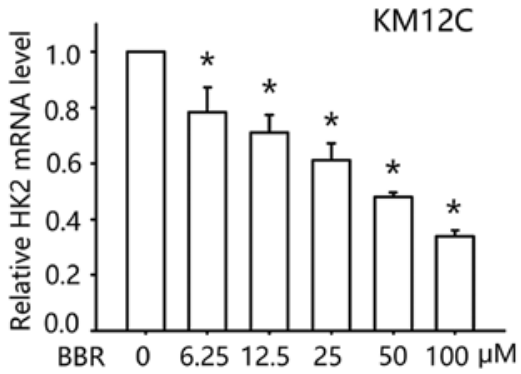

Figure 2. Berberine inhibits the transcription of glucose metabolism-related genes in colon cancer cells. (A-F) qPCR analysis of GLUT1, LDHA and HK2 in HCT116 and KM12C cells following treatment with 0-100 $\mu \mathrm{M}$ berberine (BBR) for $24 \mathrm{~h}$ (HCT116) or 15 h (KM12C). Data are expressed as mean \pm SEM, $\mathrm{n}=3,{ }^{*} \mathrm{P}<0.05$.

berberine may downregulate glucose metabolism in colon cancer cells by inhibition of the transcription of glucose metabolism-related genes.

Berberine inhibits HIF-1a expression at the posttranscriptional level. We next explored how berberine regulates the transcription of the above glucose metabolism-related genes. It is well known that the enhanced glucose uptake and glycolysis of cancer cells is partly due to highly expressed HIF-1 $\alpha$. HIF- $1 \alpha$ is upregulated in low $\mathrm{O}_{2}$ concentrations but also by oncogene activation or loss of tumor suppressors (16). Upregulated HIF-1 $\alpha$ would further facilitate the transcription of genes involved in glucose uptake and glycolysis-related genes, including GLUT1, LDHA and HK2 $(17,18)$. Therefore, we next examined the effect of berberine on the mRNA and protein level of HIF-1 $\alpha$. As determined by qPCR, we found that treatment with berberine did not alter the mRNA level of HIF1A in the HCT116 and KM12C cells (Fig. 3A and B). Western blotting demonstrated that KM12C cells expressed HIF-1 $\alpha$ protein even in normoxic condition. Treatment with $0-100 \mu \mathrm{M}$ berberine decreased the protein level in a concentration-dependent manner (Fig. 3C). These data indicated that berberine negatively modulates glucose metabolism through regulation of HIF-1 $\alpha$ at the post-transcriptional level.
Berberine suppresses HIF-1a protein synthesis by inhibition of the mTOR pathway. We then aimed to resolve whether berberine affects HIF-1 $\alpha$ degradation. It is known that HIF-1 $\alpha$ protein degradation is regulated by prolyl hydroxylation and then the ubiquitin-dependent proteasome pathway (19). Briefly, HIF-1 $\alpha$ is hydroxylated by prolyl hydroxylases (PHD1-3) at proline (Pro)-402 and -564. Hydroxylated HIF-1 $\alpha$ then binds to the von Hippel-Lindau tumor-suppressor protein (VHL). VHL is the recognition component of an E3 ubiquitin-protein and ubiquitylated HIF-1 $\alpha$ is rapidly degraded by the proteasome (20). We first treated KM12C cells with desferrioxamine (DFX), an iron chelator, which is known to inhibit hydroxylation of HIF-1 $\alpha$ by chelating the iron required for activity of the HIF-1 $\alpha$-specific proline hydroxylases, and thus blocks HIF-1 $\alpha$ degradation (21). As shown in Fig. 4A, when HIF-1 $\alpha$ degradation was blocked by DFX, berberine was still able to decrease the expression of HIF-1 $\alpha$. Similarly, treatment with proteasome inhibitor, MG132, was unable to inhibit berberine's effect on the reduction of HIF-1 $\alpha$ expression (Fig. 4B). These results demonstrated that the negative post-transcriptional regulation of berberine on HIF- $1 \alpha$ expression was not by proteasomal degradation.

We then aimed to ascertain whether berberine interrupts HIF-1 $\alpha$ protein translation. Mammalian target of 
A

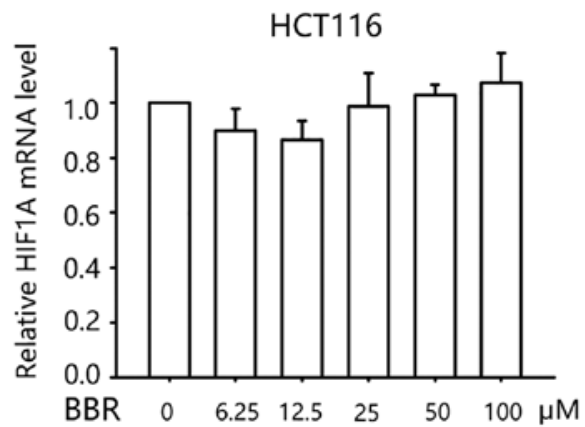

B

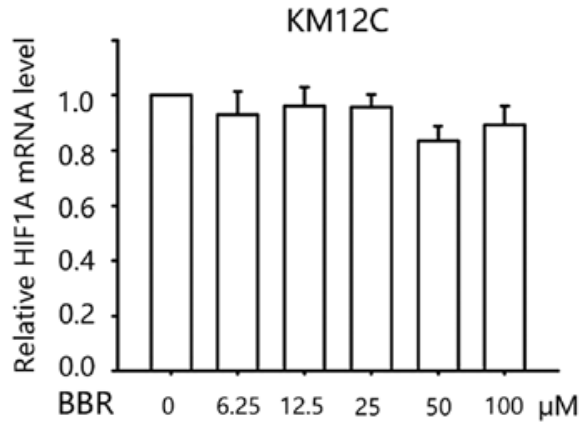

C

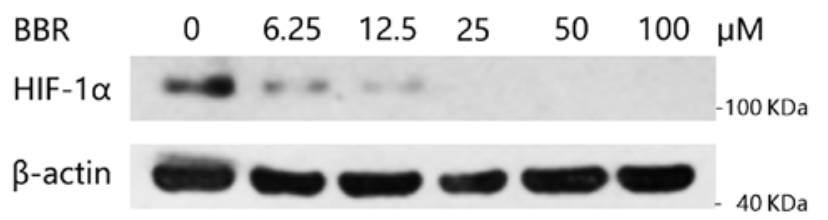

Figure 3. Berberine inhibits HIF-1 $\alpha$ expression at the post-transcriptional level. (A and B) qPCR analysis of HIF-1 $\alpha$ in HCT116 and KM12C cells following treatment with 0-100 $\mu \mathrm{M}$ berberine (BBR) for $24 \mathrm{~h}$ (HCT116) or $15 \mathrm{~h}$ (KM12C). Data are expressed as mean $\pm \mathrm{SEM}, \mathrm{n}=3$. (C) Western blot analysis showing the protein level of HIF-1 $\alpha$ in KM12C cells following treatment with different concentrations of BBR for $24 \mathrm{~h}$ (HCT116) or 15 h (KM12C).

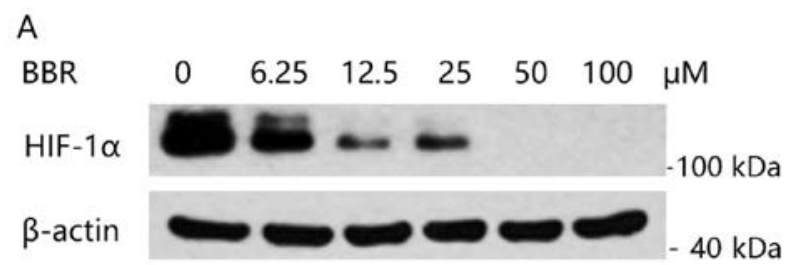

DFX treatment

B

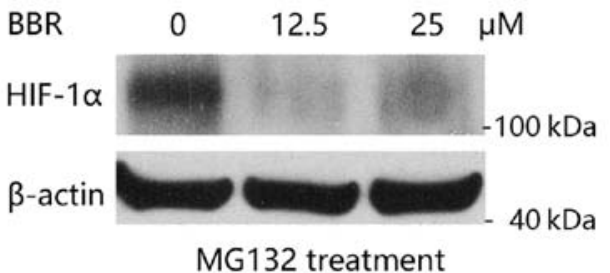

C

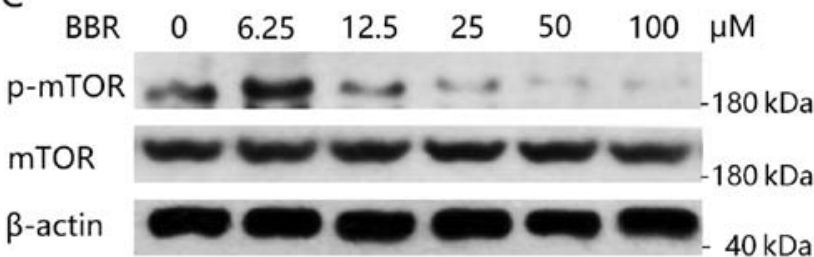

Figure 4. Berberine inhibits HIF-1 $\alpha$ protein synthesis by suppression of the mTOR pathway. (A) Western blot analysis showing the protein level of HIF-1 $\alpha$ in KM12C cells co-treated with $0-100 \mu \mathrm{M}$ berberine (BBR) and DFX $(250 \mu \mathrm{M})$ for $15 \mathrm{~h}$. (B) Western blot analysis showing the protein level of HIF-1 $\alpha$ in KM12C cells preincubated with $10 \mu \mathrm{M}$ MG132 for $2 \mathrm{~h}$ and then exposed to $0-100 \mu \mathrm{M}$ BBR for another $15 \mathrm{~h}$. (C) Western blot analysis showing the protein level of phospho-Ser2448-mTOR (p-mTOR) and total mTOR in KM12C cells following treatment with the different concentrations of BBR.

rapamycin (mTOR) activity is a major determinant of the rate of HIF-1 $\alpha$ protein synthesis $(22,23)$. We then detected the activity of the mTOR pathway in KM12C cells after the treatment of berberine. As shown in Fig. 4C, berberine significantly inhibited the phosphorylation of mTOR (p-mTOR) while not altering the total expression level of mTOR protein. Taken together, our data indicated that berberine inhibits HIF-1 $\alpha$ protein expression by inhibition of the mTOR pathway, and thereby interruption of HIF-1 $\alpha$ protein synthesis.

\section{Discussion}

In the present study, we demonstrated that berberine inhibits glucose uptake and cell growth in colon cancer cells. This effect is mediated by the inhibition of the mTOR pathway, which leads to the suppression of HIF-1 $\alpha$ protein synthesis. The reduction in the HIF-1 $\alpha$ expression level may attenuate the transcription activity of HIF- $1 \alpha$ and decrease the transcription of glucose metabolism-related genes, GLUT1, LDHA and HK2.

The main mechanism by which berberine exerts antidiabetic effects relates to its glucose-lowering activity. It has been reported that berberine improves glucose uptake in glucose-consuming tissues, such as adipose, liver or muscle cells $(5,6,13,24,25)$. In the present study, we revealed that berberine inhibited colon cancer cell glucose uptake and metabolism, which is in contrast from what has been reported in normal cells. Berberine has been considered as an anticancer drug with low toxicity to normal cells (26-28). For example, Inoue et al reported that berberine showed higher cytotoxicity against five human oral squamous cell carcinomas (HSC-2, HSC-3, HSC-4, NA and CA9-22) and one human promyelocytic leukemia (HL-60) cell line, when compared with normal human oral tissue-derived cells (gingival fibroblasts, pulp cells and periodontal ligament fibroblasts) (26). Chidambara et al reported that berberine inhibited proliferation of colon cancer cells (SW480) but showed low toxicity to normal colon cells (CCD-CoN112) (29). The mechanisms for this tumor-specific selective toxicity of berberine remains elusive. Since tumor cells exhibit higher levels of glucose uptake and glycolytic metabolism as compared to 
normal cells owing to upregulated HIF-1 $\alpha$ expression, the differential effect of berberine on glucose uptake between normal and cancer cells may attribute to the selectivity of berberine for cancer-targeted treatment.

HIF-1 $\alpha$ was initially identified due to its response to low $\mathrm{O}_{2}$ concentrations, but it can also be regulated by oncogene activation or loss of tumor suppressors. Therefore, upregulation of HIF- $1 \alpha$ is quite common in many human cancers. HIF-1 $\alpha$ overexpression is associated with increased patient mortality in many different types of cancer (16). Inhibition of HIF-1 $\alpha$ activity has marked effects on tumor growth and is considered as an anticancer therapeutic strategy $(30,31)$. In the present study, we identified berberine as a novel HIF-1 $\alpha$ inhibitor that could be used for colon cancer treatment. Berberine reduced HIF-1 $\alpha$ expression in normoxia and also hypoxia conditions (DFX treatment is considered as a hypoxia mimic). Given the different expression of HIF-1 $\alpha$ in tumor and normal cells, the effect of berberine on HIF-1 $\alpha$ may account for its selective toxicity in cancer. Consistent with our research, there are several studies that have reported the inhibitory effect of berberine on HIF-1 $\alpha$ expression in other types of cancers, such as esophageal squamous cancer (32), gastric adenocarcinoma cell line SC-M1 (33), nasopharyngeal carcinoma (34) and prostate cancer (35).

The mTOR kinase integrates and transmits signals from a diverse array of signaling pathways to regulate cell survival and growth. Activated mTOR stimulates protein synthesis and cell growth through phosphorylation of ribosomal protein S6 kinase (p70S6K), eukaryotic initiation factor $4 \mathrm{E}$ binding protein 1 (4E-BP1) and eukaryotic elongation factor 2 kinase (EEF2K) (36). The mTOR pathway consists of the downstream effectors of PI3K-AKT signaling (37). It is reported that berberine inhibits PI3K-AKT signaling in colorectal cancer cells and melanoma cells $(38,39)$. Our finding that berberine suppresses mTOR activity may be due to its effects on the PI3K/AKT pathway. Between the two colon cancer cell lines that we tested, HCT116 cells were much more sensitive to berberine than $\mathrm{KM} 12 \mathrm{C}$ cells. One of the differences between HCT116 and KM12C cells is that KM12C cells are PTEN-loss, while HCT116 cells are PTEN-competent. PTEN is an upstream inhibitory mediator to mTOR. The loss of PTEN in KM12C cells may lead to increased mTOR expression, which may affect the sensitivity to berberine (40).

In conclusion, the present study reveals a new role of berberine in the inhibition of tumor glucose uptake. The results not only suggest a possible mechanism involved in berberine's tumor selectivity but also disclose a promising therapeutic effect of berberine in colon cancer treatment.

\section{Acknowledgements}

Not applicable.

\section{Funding}

The present study was supported by grants from the National Natural Science Foundation of China (No. 81602560 to XH, No. 81572589 to YYZ and No. U1405228 to TH) and grants from the Natural Science Foundation of Fujian Province (No. 2017J06020 to YYZ and No. 2016J01410 to XH).

\section{Availability of data and materials}

The datasets used and analyzed in the present study are available from the corresponding author upon reasonable request.

\section{Authors' contributions}

YYZ and $\mathrm{XH}$ designed the experiments and wrote the manuscript. LM, QC, KG, XX, YX, WZ and HC carried out the molecular and cellular experiments. TH was involved in the design of this project. All authors have read and approved the manuscript and have agreed to be accountable for all aspects of the research in ensuring that the accuracy or integrity of any part of the work are appropriately investigated and resolved.

\section{Ethics approval and consent to participate}

Not applicable.

\section{Consent for publication}

Not applicable.

\section{Competing interests}

The authors declare that they have no competing interests.

\section{References}

1. Hsu PP and Sabatini DM: Cancer cell metabolism: Warburg and beyond. Cell 134: 703-707, 2008.

2. Denko NC: Hypoxia, HIF1 and glucose metabolism in the solid tumour. Nat Rev Cancer 8: 705-713, 2008.

3. Cicero AF and Tartagni E: Antidiabetic properties of berberine: From cellular pharmacology to clinical effects. Hosp Pract 40: 56-63, 2012.

4. Pang B, Zhao LH, Zhou Q, Zhao TY, Wang H, Gu CJ and Tong XL: Application of berberine on treating type 2 diabetes mellitus. Int J Endocrinol 15: 905749, 2015.

5. Cok A, Plaisier C, Salie MJ, Oram DS, Chenge J and Louters LL: Berberine acutely activates the glucose transport activity of GLUT1. Biochimie 93: 1187-1192, 2011.

6. Zhou L, Yang Y, Wang X, Liu S, Shang W, Yuan G, Li F, Tang J, Chen $\mathrm{M}$ and Chen J: Berberine stimulates glucose transport through a mechanism distinct from insulin. Metabolism 56: 405-412, 2007.

7. Cheng Z, Pang T, Gu M, Gao AH, Xie CM, Li JY, Nan FJ and Li J: Berberine-stimulated glucose uptake in L6 myotubes involves both AMPK and p38 MAPK. Biochim Biophys Acta 1760: 1682-1689, 2006.

8. Ortiz LM, Lombardi P, Tillhon M and Scovassi AI: Berberine, an epiphany against cancer. Molecules 19: 12349-12367, 2014.

9. Wang N, Tan HY, Li L, Yuen MF and Feng Y: Berberine and Coptidis Rhizoma as potential anticancer agents: Recent updates and future perspectives. J Ethnopharmacol 176: 35-48, 2015.

10. Tan W, Li Y, Chen M and Wang Y: Berberine hydrochloride: Anticancer activity and nanoparticulate delivery system. Int $\mathbf{J}$ Nanomedicine 6: 1773-1777, 2011.

11. Zou C, Wang Y and Shen Z: 2-NBDG as a fluorescent indicator for direct glucose uptake measurement. J Biochem Biophys Methods 64: 207-215, 2005.

12. Livak KJ and Schmittgen TD: Analysis of relative gene expression data using real-time quantitative PCR and the $2^{-\Delta \Delta C_{\mathrm{T}}}$ method. Methods 25: 402-408, 2001.

13. Kim SH, Shin EJ, Kim ED, Bayaraa T, Frost SC and Hyun CK: Berberine activates GLUT1-mediated glucose uptake in 3T3-L1 adipocytes. Biol Pharm Bull 30: 2120-2125, 2007. 
14. Haber RS, Rathan A, Weiser KR, Pritsker A, Itzkowitz SH, Bodian C, Slater G, Weiss A and Burstein DE: GLUT1 glucose transporter expression in colorectal carcinoma: A marker for poor prognosis. Cancer 83: 34-40, 1998.

15. Saigusa S, Toiyama Y, Tanaka K, Okugawa Y, Fujikawa H, Matsushita K, Uchida K, Inoue Y and Kusunoki M: Prognostic significance of glucose transporter-1 (GLUT1) gene expression in rectal cancer after preoperative chemoradiotherapy. Surg Today 42: 460-469, 2012.

16. Semenza GL: Targeting HIF-1 for cancer therapy. Nat Rev Cancer 3: 721-732, 2003.

17. Koppenol WH, Bounds PL and Dang CV: Otto Warburg's contributions to current concepts of cancer metabolism. Nat Rev Cancer 11: 325-337, 2011.

18. Semenza GL: Regulation of cancer cell metabolism by hypoxia-inducible factor 1. Semin Cancer Biol 19: 12-16, 2009.

19. Kallio PJ, Wilson WJ, O'Brien S, Makino Y and Poellinger L: Regulation of the hypoxia-inducible transcription factor lalpha by the ubiquitin-proteasome pathway. J Biol Chem 274 6519-6525, 1999.

20. Lee JW, Bae SH, Jeong JW, Kim SH and Kim KW: Hypoxia-inducible factor (HIF-1)alpha: Its protein stability and biological functions. Exp Mol Med 36: 1-12, 2004.

21. Demidenko ZN, Rapisarda A, Garayoa M, Giannakakou P, Melillo G and Blagosk lonny MV: Accumulation of hypoxia-inducible factor-1alpha is limited by transcription-dependent depletion. Oncogene 24: 4829-4838, 2005.

22. Abraham RT: mTOR as a positive regulator of tumor cell responses to hypoxia. Curr Top Microbiol Immunol 279: 299-319, 2004.

23. Masoud GN and Li W: HIF-1 $\alpha$ pathway: Role, regulation and intervention for cancer therapy. Acta Pharm Sin B 5: 378-389, 2015.

24. Yi P, Lu FE, Xu LJ, Chen G, Dong H and Wang KF: Berberine reverses free-fatty-acid-induced insulin resistance in 3T3-L1 adipocytes through targeting IKKbeta. World J Gastroenterol 14 876-883, 2008

25. Zhang CH, Yu RY, Liu YH, Tu XY, Tu J, Wang YS and Xu GL: Interaction of baicalin with berberine for glucose uptake in 3T3-L1 adipocytes and HepG2 hepatocytes. J Ethnopharmaco 151: 864-872, 2014

26. Inoue K, Kulsum U, Chowdhury SA, Fujisawa S, Ishihara M, Yokoe I and Sakagami H: Tumor-specific cytotoxicity and apoptosis-inducing activity of berberines. Anticancer Res 25: 4053-4059, 2005.

27. Liu B, Wang G, Yang J, Pan X, Yang Z and Zang L: Berberine inhibits human hepatoma cell invasion without cytotoxicity in healthy hepatocytes. PLoS One 6: e21416, 2011.
28. Wang L, Liu L, Shi Y, Cao H, Chaturvedi R, Calcutt MW, Hu T, Ren X, Wilson KT, Polk DB and Yan F: Berberine induces caspase-independent cell death in colon tumor cells through activation of apoptosis-inducing factor. PLoS One 7: e36418, 2012.

29. Chidambara Murthy KN, Jayaprakasha GK and Patil BS: The natural alkaloid berberine targets multiple pathways to induce cell death in cultured human colon cancer cells. Eur J Pharmacol 688: 14-21, 2012.

30. Yu T, Tang B and Sun X: Development of Inhibitors Targeting hypoxia-inducible factor 1 and 2 for cancer therapy. Yonsei Med J 58: 489-496, 2017.

31. Melillo G: Targeting hypoxia cell signaling for cancer therapy. Cancer Metastasis Rev 26: 341-352, 2007.

32. Yang X, Yang B, Cai J, Zhang C, Zhang Q, Xu L, Qin Q, Zhu H, Ma J, Tao G, et al: Berberine enhances radiosensitivity of esophageal squamous cancer by targeting HIF-1 $\alpha$ in vitro and in vivo. Cancer Biol Ther 14: 1068-1073, 2013.

33. Lin S, Tsai SC, Lee CC, Wang BW, Liou JY and Shyu KG: Berberine inhibits HIF-1 alpha expression via enhanced proteolysis. Mol Pharmacol 66: 612-619, 2004.

34. Zhang C, Yang X, Zhang Q, Yang B, Xu L, Qin Q, Zhu H, Liu J, Cai J, Tao G, et al: Berberine radiosensitizes human nasopharyngeal carcinoma by suppressing hypoxia-inducible factor-1 $\alpha$ expression. Acta Otolaryngol 134: 185-192, 2014.

35. Zhang Q, Zhang C, Yang X, Yang B, Wang J, Kang Y, Wang Z, Li D, Huang G, Ma Z, et al: Berberine inhibits the expression of hypoxia induction factor-1alpha and increases the radiosensitivity of prostate cancer. Diagn Pathol 9: 98, 2014.

36. Dazert E and Hall MN: mTOR signaling in disease. Curr Opin Cell Biol 23: 744-755, 2011

37. Engelman JA: Targeting PI3K signalling in cancer: Opportunities, challenges and limitations. Nat Rev Cancer 9: 550-562, 2009.

38. Chen ZZ: Berberine induced apoptosis of human osteosarcoma cells by inhibiting phosphoinositide 3 kinase/protein kinase B (PI3K/Akt) signal pathway activation. Iran J Public Health 45: 578-585, 2016.

39. Kou Y, Li L, Li H, Tan Y, Li B, Wang K and Du B: Berberine suppressed epithelial mesenchymal transition through cross-talk regulation of PI3K/AKT and RAR $\alpha / R A R \beta$ in melanoma cells. Biochem Biophys Res Commun 479: 290-296, 2016.

40. Milella M, Falcone I, Conciatori F, Matteoni S, Sacconi A, De Luca T, Bazzichetto C, Corbo V, Simbolo M, Sperduti I, et al: PTEN status is a crucial determinant of the functional outcome of combined MEK and mTOR inhibition in cancer. Sci Rep 7: 43013, 2017. 